\title{
A PROFILE OF NOMIFENSINE
}

\author{
G.W. HANKS \\ Medical Department, Hoechst Pharmaceuticals, Hoechst House, Salisbury Road, Hounslow, \\ Middlesex TW4 6JH, UK
}

1 Nomifensine is a new antidepressant of novel chemical structure (a tetrahydroisoquinoline) with a pharmacological and therapeutic profile which differentiates it from any existing group of psychotropic agents.

2 The basic animal pharmacological profile is similar to that of the tricyclic antidepressants, imipramine and desmethylimipramine, but with a comparative lack of peripheral anticholinergic and cardiotoxic effects.

3 The pattern of effects on monoamine neurotransmitters is unique amongst antidepressants in that nomifensine is a potent dopamine agonist, has a powerful inhibitory effect on noradrenaline uptake and a weaker inhibitory effect on serotonin uptake. These pharmacological differences are reflected in the behavioural activity of the drug.

4 Clinically nomifensine has been shown to be an effective non-sedative antidepressant; its relative lack of anticholinergic and other somatic side-effects (particularly on the cardiovascular system) have been confirmed in patients.

\section{Introduction}

It is just twenty years ago that Kuhn accidentally discovered the antidepressant properties of imipramine (Kuhn, 1957). At about the same time the monoamine oxidase (MAO) inhibitors were introduced for the treatment of depression (Loomers et al., 1957) following the observation that the antituberculous drugs, isoniazid and iproniazid, had mood-elevating properties, and the demonstration of their action on MAO (Zeller et al., 1952). These two groups of drugs radically changed the management of depressive illness.

The imipramine-like drugs, which became known as the 'tricyclics' because of their three-ringed molecule, have proved to be the more effective, consistent and safer, and have become the drugs of first choice in the treatment of depression (Byck, 1975). For this reason there have been many attempts to modify and thereby improve upon the original members of this group, imipramine and amitriptyline (Finch, 1975) but none of the newer tricyclics has represented a really significant advance from the clinical standpoint (Hollister, 1976).

The Monthly Index of Medical Specialities (MIMS) is a publication familiar to all UK clinicians and lists proprietary drugs which are currently available. The latest issue has 43 antidepressant preparations recorded, and during the course of the past two days we have heard in detail about another new antidepressant, nomifensine (Merital). One is bound to speculate why there are so many, and more pertinently "Why another?".

The answer to the first question is fairly uncontroversial. The tricyclics are the most effective antidepressant drugs available but suffer from significant drawbacks; namely a latent period before the onset of their antidepressant effect, a high incidence of unwanted effects and serious toxic (notably cardiovascular) reactions in some patients. There remains, therefore, room for improvement. Some would go further and say that we are still a long way from specific, potent psychotropic agents, including antidepressants (Grahame-Smith, 1975).

A complete answer to the second part of the question is more difficult but the data which have been presented during the course of this conference constitute a cogent and persuasive response. The purpose of this final paper is to attempt to summarize the important facts, some of which have been highly complex and technical, and put them into perspective for the clinician treating depressed patients. It is the doctor faced with a patient who must make the decision whether or not to use a new drug for that particular patient. In reaching that decision he is concerned with fundamental considerations: does the drug work; how does it compare with standard drugs; what, if any, are its advantages? 


\section{Efficacy}

Data on a large number of patients who have been involved in the clinical evaluation of nomifensine have been presented. Several speakers have described in detail controlled trials against placebo and against standard drugs, which have shown consistently that nomifensine works. It is an effective antidepressant and seems to be, in this respect, at least comparable to the standard drugs, imipramine and amitriptyline.

Clearly, we need to be able to start from this basis before going on to assess the characteristics of nomifensine that differentiate it from other effective antidepressants.

\section{Chemistry and pharmacology}

Dr Hoffman described the novel chemical structure of nomifensine (a tetrahydroisoquinoline) which seems to be reflected in unique pharmacological properties, such that it cannot be categorised in terms of any existing group of psychotropic agents.

The basic animal pharmacological profile of nomifensine is similar to that of imipramine, but the relative lack of cardiovascular and peripheral anticholinergic effects was apparent at the outset (Hoffman, 1973). Investigations of its effects on central monoamine neurotransmitters have revealed other significant differences.

It is widely believed that the ability of antidepressants to affect central amine neurotransmitters may be the basis of their behavioural activity (Shepherd et al., 1968). The tricyclics inhibit the re-uptake of noradrenaline (NA) and/or 5-hydroxytryptamine (5-HT) by the presynaptic nerve terminal (Carlsson, 1967). None of this group of drugs has any significant effect on dopamine DA (Horn et al., 1971). The result of this reuptake inhibition is that the amine transmitters persist in the synaptic cleft, with a consequent potentiation of their action.

This particular property of tricyclic antidepressants fits very nicely, and indeed helped to evolve, the monoamine hypothesis of affective disorders; as does the effect of the MAO inhibitors in increasing free amine levels within the cell by preventing their degradation. The 'amine hypothesis' is now a familiar concept and simply proposes that a deficiency of central catecholamines, particularly NA, is associated with depression, whereas an excess is associated with manic states (Schildkraut, 1965). An alternative theory emphasises the central role of 5-HT rather than the catecholamines (Coppen, 1968). DA has received little attention or emphasis in this context.

Obviously the monoamine hypothesis is an oversimplification of a complex biological state, but in a modified form (MRC Brain Metabolism Unit,
1972) it can provide a baseline for the study of the pathophysiology of affective disorders, and the mode of action of the drugs used in their treatment.

Using synaptosome preparations, nomifensine has been shown to be a very powerful inhibitor of NA uptake, with a weaker effect on 5-HT, and thus is similar to many tricyclics in respect of these two amines (Schacht \& Heptner, 1974). In contrast to the tricyclics, however, nomifensine has a powerful inhibitory effect on DA uptake mechanisms (Hunt et al., 1974). These potent and unique characteristics were confirmed in a different model by the platelet studies of Miss Ehsanullah and Professor Turner. Dr Costall has presented evidence that nomifensine has, in addition, a direct effect on DA receptors (Costall et al., 1975) and this has been discussed in the light of clinical data from the trials in Parkinson's disease and the endocrine studies.

It was apparent from these investigations that nomifensine possessed significantly different pharmacological properties from the tricyclics. That this may have clinical implications has been suggested by an observation in some early trials that schizophrenic patients on long-term neuroleptic therapy experienced an amelioration of extrapyramidal side-effects when nomifensine was added to their treatment. In some cases, schizophrenic symptoms were exacerbated. There were several indications therefore that the drug may be useful in Parkinson's disease and in some endocrine disorders, as well as in depression, and the use of nomifensine in these conditions has been evaluated in the clinic.

The results of studies in parkinsonian patients which have been completed suggest that the drug certainly has a moderate therapeutic effect in Parkinson's disease but that it is not of the same order as L-DOPA.

The endocrine studies with nomifensine have produced rather more complicated results and have been somewhat difficult to interpret, but they permit the conclusion that nomifensine has no clinically significant effects on the endocrine system in the dose range used in the treatment of depressive illness.

What these studies have emphasised, however, is that the DA agonist effect of nomifensine, which is seen in animal and human models, is apparent also in the clinic. The situation is obviously complex and these studies have not helped elucidate the relative contributions of the pre- and postsynaptic components of the dopaminergic effect of nomifensine.

What of the relevance of the dopaminergic activity of nomifensine to its antidepressant effect, a question posed by Bedard et al. (1977) in his paper? The answer must still be speculative. There is increasing interest in the role of DA in the control of mood and its involvement in the aetiology of affective disorders (Randrup et al., 1975). There is evidence that 
dopaminergic systems may provide overall control of the general level of arousal and motivation (Ungerstedt, 1971; Eccleston, 1975) and since the observation by Ehringer \& Hornykiewicz (1960) that the basal ganglia of patients who died with Parkinson's disease were depleted of DA, there has accumulated considerable evidence relating to the function of dopaminergic systems in the control of motor activity (Barnett, 1975).

It is well known that severely depressed patients exhibit an inhibitory syndrome, with retardation of thought and activity. Nomifensine, uniquely, has powerful effects on both DA and NA. There is a theoretical basis therefore to suggest that nomifensine may have an effect on these motor signs and symptoms of depressive illness as well as on mood. Data from several clinical trials have revealed that these effects have been demonstrated clinically. Nomifensine may well be the first of a new group of antidepressants with effects on both noradrenergic and dopaminergic systems-on mood and on 'motivation'.

\section{Pharmacokinetics}

Dr Lader (1977) has discussed briefly the importance of the pharmacokinetics of antidepressant drugs, a subject of considerable current interest (Luchins \& Ananth, 1976). Since it was shown that there is enormous variation in blood levels in patients receiving the same dose of a tricyclic antidepressant (Hammer \& Sjöqvist, 1967), a large number of studies have investigated the relationship between blood levels of various tricyclics and therapeutic response. The evidence is contradictory and no acceptable conclusion has been reached. A major difficulty, not confined to psychotropic drugs, is that the concentration of a drug or active metabolite at the appropriate receptor may not bear a direct relationship to the circulating blood level. A problem particularly relevant to tricyclic antidepressants is the lack of uniformity of diagnosis of depressive disorders, and of analytical methods of drug assay (Braithwaite \& Goulding, 1975).

This sort of data for nomifensine is not yet available because the relevant clinical trials are still continuing. The details of the kinetics of nomifensine in normal subjects, however, have been described. The drug is rapidly and completely absorbed and excreted almost entirely by the kidneys. An important kinetic parameter of antidepressants is the plasma half-life, and here again nomifensine differs greatly from the tricyclics. It has an elimination half-life of about $2 \mathrm{~h}$ compared with the $20-60 \mathrm{~h}$ or more of the various tricyclics. This has obvious clinical implications, particularly with regard to the management of overdosage.

\section{Speed of onset of action and adverse effects}

In clinical practice the latent period of onset of the tricyclics and the high incidence of adverse effects may be difficult problems to deal with. Recent surveys have shown that adverse effects of tricyclics are almost certainly the cause of poor patient compliance, and indeed of a reluctance by the prescribing physician to give an adequate dose (Johnson, 1974; Ketai, 1976). These are two important reasons for failure to respond to treatment. Grof et al. (1977) mentioned the rapid onset of effect which he observed with nomifensine, and this has been apparent in several other trials. Just how significant this is will only become clear when the drug is in general use, but none of the controlled trials to date has shown that nomifensine works significantly faster than the tricyclic antidepressants with which it has been compared.

The adverse effects of the tricyclics, particularly the anticholinergic effects, are well known. More serious is the cardiotoxicity of these drugs (Jefferson, 1975; Burrows et al., 1976). Various tricyclic drugs may produce (orthostatic) hypotension, which is more marked in patients with pre-existing heart disease (Muller et al., 1961), ECG abnormalities and arrhythmias (Kristiansen, 1961) which may be the cause of sudden unexpected death (Moir et al., 1972). The mechanisms involved are: the anticholinergic effect, the blockade of catecholamine uptake systems with a consequential increase in the levels of circulating catecholamines, impairment of distal conduction and, at a high dosage, a direct negative inotropic effect on the myocardium (Jefferson, 1975).

The initial animal studies with nomifensine demonstrated a relative lack of cardiovascular and anticholinergic effects (Hoffman, 1973). Several groups of investigators have specifically examined the cardiovascular effects of nomifensine, because of its apparent lack of cardiotoxicity. Garattini's group in Milan have a particular interest in this problem. Using isolated rat atria as a model, they have demonstrated that nomifensine is ten times less potent than desipramine in inhibiting ${ }^{3} \mathrm{H}-\mathrm{NA}$ uptake in the heart, and is also removed from the tissue at a higher rate than desipramine (Hoechst AG, internal report).

Other animal studies involved comparisons of infusions of nomifensine, imipramine and amitriptyline in guinea-pigs. The reduction in heart rate and prolongation of the $P Q$ interval were much less pronounced after nomifensine than after either of the other drugs. The most striking difference was the minimal effect of nomifensine on the QRS interval, compared with the considerable prolongation produced by the tricyclics (Hoechst AG, internal report).

Biamino et al., in the course of diagnostic cardiac catheterisations in ten patients, demonstrated that 
nomifensine $100 \mathrm{mg}$ caused no significant changes in heart rate, cardiac output, mean arterial pressure, pulmonary artery pressure or end-diastolic left ventricular pressure. No ECG changes were recorded during a 90-min observation period following oral administration of nomifensine $100 \mathrm{mg}$ (Biamino, 1976). Biamino's group had earlier demonstrated a total lack of negative inotropic effect of nomifensine, using isolated cat papillary muscle (Biamino et al., 1975).

A 4-week tolerability study in $\mathbf{4 0}$ healthy subjects failed to reveal any effect of nomifensine on blood pressure or ECG (Hoechst AG, internal report). A patient who took an overdose of 95 capsules of nomifensine $25 \mathrm{mg}$ suffered no adverse cardiovascular effects and recovered (Hoechst AG, internal report).

There is already considerable evidence, therefore, that nomifensine is significantly less cardiotoxic than the standard tricyclic antidepreseants.

A considerable amount of data has been collated relating to side-effects observed in the clinical trials with nomifensine overseas. Notable is the relative absence of somatic, particularly anticholinergic effects, and a predominance of psychological sideeffects, a pattern predictable from the pharmacological profile of the drug in animals. The paper by McClelland et al. (1977) highlighted a specific difference in the incidence and severity of 'dry mouth', with nomifensine and amitriptyline, a finding which has been observed in several other studies. A double-blind study was carried out in which measurements were made of salivary flow in patients receiving nomifensine, placebo or an amitriptyline/chlordiazepoxide combination. The results indicated that the nomifensine and placebo effects were not significantly different with little effect on salivary secretion, whereas the tricyclic/benzodiazepine combination produced a pronounced reduction in salivary flow (Malsch, 1976).

A further important safety factor for nomifensine has been indicated by the experimental studies in baboons of Trimble et al. (1977). If the apparent mild anticonvulsant effect of nomifensine is confirmed in human patients this would have important clinical implications, particularly with regard to epileptic depressed patients, since the tricyclics have been shown to increase fit frequency in such patients. Once more this particular property of nomifensine seems to be related to its dopaminergic action.

The imipramine-like drugs are known to produce sedation of varying degree (and this has in fact been postulated as their only basic pharmacodynamic action (Jaäskelainen \& Viukari, 1976). In agitated and suicidal patients this can be used to advantage but in many patients treated outside hospital, sedation may be seriously disabling. Nomifensine has been shown to produce minimal, if any sedation. Other studies have shown that it also has no deleterious effects on psychomotor performance (Wittenborn et al., 1976), and that there is no, potentiation of alcohol by nomifensine (Taeuber et al., 1976).

In these respects nomifensine again differs significantly from currently available antidepressants. This is of importance for appropriate prescribing: as nomifensine is non-sedative, severely agitated patients should not receive nomifensine in isolation, but probably together with a tranquilliser.

The other group of patients in whom nomifensine should be used with caution is that group of patients with schizoaffective disorders. Here, nomifensine should be used in conjunction with a neuroleptic.

Otherwise, nomifensine has been shown to be effective and appropriate over the whole spectrum of depressive illness.

In summary, the data presented in this paper have shown that nomifensine is an effective, non-sedative antidepressant; it is chemically and pharmacologically unique: it seems to be safe and very well tolerated.

A recent detailed review of antidepressants, past, present and future says of nomifensine: "a good antidepressant action with a mild central stimulating effect was reported to have been observed in man. If this profile, and the claims of efficacy and tolerability, are substantiated by well controlled studies against imipramine and amitriptyline, then nomifensine will become a significant new development in antidepressant therapy." (Finch, 1975).

The profile, the efficacy and the tolerability of nomifensine have been confirmed. Shortly, the drug will become generally available, so that the final statement above may be put to the test.

\section{References}

BARNETT, A. (1975). Dopamine receptors and their role in brain functions. In Current Developments in Psychopharmacology, 1, 2-35, ed. Essman, W.B. \& Valzelli, L. New York: Spectrum.

BEDARD, P., PARKES, J.D. \& MARSDEN, C.D. (1977). Nomifensine in Parkinson's disease. Br. J. clin. Pharmac. 4. $187 \mathrm{~S}-190 \mathrm{~S}$.
BIAMINO, G., NÖRING, J., NEYE, G \& NEYE, J. (1975). Wirkung von trizyklischen Antidepressiva und von Nomifensin (HOE 984) auf die kontraktilen Eigenschaften des isolierten Papillarmuskels und auf den Tonus der glatten Gefässmuskulatur. Z. Kardiol., 64, suppl. 2, 90.

BIAMINO. G. (1977). Die kardiotoxische Wirkung 
trizyklischer Antidepressiva. In Alival Symposium über Ergebnisse der experimentellen und klinischen Prüfung, Berlin 1st-2nd October, 1976. Stuttgart and New York: Schattauer.

BRAITHWAITE, R.A. \& GOULDING, R. (1975). Effective dosage of tricyclic antidepressants. Br. med. J., 1, 206.

BURROWS, G., VOHRA, J., HUNT, D., SLOMAN, J., SCOGGINS, B. \& DAVIES, B. (1976). Cardiac effects of different tricyclic antidepressant drugs. Br. J. Psychiat., 129, 335-341.

BYCK, R. (1975). Drugs and the treatment of psychiatric disorders. In The Pharmacological Basis of Therapeutics, fourth ed, 152-196, ed. Goodman, L.S. \& Gilman, A. London: Bailliere Tindall.

CARLSSON, A. (1967). Recent studies on the mode of action of antidepressive drugs. Naunyn-Schmiedeberg's Arch. exp. Path. Pharmak., 257, 115-117.

COPPEN, A.J. (1968). Depressed states and indolealkylamines. In Advances in Pharmacologv. 6, Part B, ed. Garattini, S. \& Shore, P.A. New York: Academic.

COSTALL, B., KELLY, D.M. \& NAYLOR, R.J. (1975). Nomifensine: a potent dopaminergic agonist of antiparkinson potential. Psychopharmacologia Berl., 41, 153-164.

ECCLESTON, D. (1975). Modern views on diagnosis and classification of depressions. 11. United Kingdom. J. Int. med. Res., 3, suppl. 3, 3-6.

EHRINGER, H. \& HORNYKIEWICZ, O. (1960). Verteilung von Noradrenalin und Dopamin (3hydroxytyramin) in Gehirn des Menschen und ihr Verhalten bei Erkrankungen des extrapyramidalen Systems. Klin. Wschr., 38, 1236-1239.

FINCH, N. (1975). Chemical approaches to the development of antidepressants. In Antidepressants, 1-58, ed. Fielding, S. \& Lal, H. New York: Futura.

GRAHAME-SMITH, D.G. (1975). Self-medication with mood-changing drugs. J. med. Ethics, 1, 132-137.

GROF, P., SAXENA, B., DAIGLE, L. \& MAHUTTE, G. (1977). Dopaminergic agonist nomifensine compared with amitriptyline: A double-blind clinical trial in acute primary depressions. Br. J. clin Pharmac. 4, $221 \mathrm{~S}-225 \mathrm{~S}$.

HAMMER, W \& SJÖQVIST, F. (1967). Plasma levels of monomethylated tricyclic antidepressants during treatment with imipramine-like compounds. Life Sci., 6, 1895-1903.

HOFFMAN, I. (1973). 8-amino-2-methyl-4-phenyl-1,2,3,4tetrahydroisoquinoline, a new antidepressant. Arzneimittel-Forsch., 23, 45-50.

HOLLISTER, L.E. (1976). Clinical use of tricyclic antidepressants. Dis. Nerv. Syst., 37, 17-21.

HORN, A.S., COYLE, J.T. \& SNYDER, S.H. (1971). Catecholamine uptake by synaptosomes from rat brain. Structure-activity relationships of drugs with differential effects on dopamine and norepinephrine neurons. Molec. Pharmac., 7, 66-80.

HUNT, P., KANNENGIESSER, M.H. \& RAYNAUD, J.P. (1974). Nomifensine: a new potent inhibitor of dopamine uptake into synaptosomes from rat brain corpus striatum. J. Pharm. Pharmac., 26, 370-371.

JÄ̈̈SKELÄINEN, J. \& VIUKARI, N. (1976). Do tricyclic antidepressants work? Lancet, i, 424.

JEFFERSON, J.W. (1975). A review of cardiovascular effects and toxicity of tricyclic antidepressants. Psychosom. Med., 37, 160-179.
JOHNSON, D. (1974). A study of the use of antidepressant medication in general practice. Br. J. Psychiat., 125, 186192.

KETAI, R. (1976). Family practitioners' knowledge about treatment of depressive illness. J. Am. med. Ass., 235, 2600-2603.

KRISTIANSEN, E.S. (1961). Cardiac complications during treatment with imipramine. Acta psychiat. (Kbh), 36, $427-442$.

KUHN, R. VON (1957). Über die Behandlung depressiver Zustände mit einem Iminodibenzylderivat (G 22355). Schweiz. med. Wschr., 87, 1135-1140.

LADER, M. (1977). Human pharmacology of antidepressives. Br. J. clin. Pharmac., 4, 135S-141S.

LOOMER, H.P., SAUNDERS, J.C. \& KLINE, N.S. (1957). $A$ clinical and pharmacodynamic evaluation of iproniazid as a psychic energizer. Psychiat. Res. Rep. Am. psychiat. Ass., 8, 129-141.

LUCHINS, D. \& ANANTH, J. (1976). Therapeutic implications of tricyclic antidepressant plasma levels. $J$. nerv. ment. Dis., 162, 430-436.

MALSCH, V. (1977). Zur Frage der anticholinergen und akuten psychotropen Wirkung von Nomifensin. In Alival Symposium über Ergebnisse der experimentellen und klinischen Prüfung, Berlin 1st-2nd October, 1976. Stuttgart and New York: Schattauer.

McCLELLAND, H.A., KERR, T.A. \& LITTLE, J.C. (1977). A clinical comparison of nomifensine and amitriptyline. Br. J. clin. Pharmac. 4, 233S-236S

MOIR, D.C., CROOKS, J., CORNWELL, W.B., O'MALLEY, K., DINGWALL-FORDYCE, I., TURNBULL, M.J. \& WEIR, R.D. (1972). Cardiotoxicity of amitriptyline. Lancet, ii, 561-564.

MRC Brain Metabolism Unit. (1972). Modified amine hypothesis for the aetiology of affective illness. Lancet, ii, 573-577.

MULLER, O.F., GOODMAN, N. \& BELLET, S. (1961). The hypotensive effect of imipramine hydrochloride in patients with cardiovascular disease. Clin. Pharmac. Ther., 2, 300-307.

RANDRUP, A., MUNKVAD, I., FOG, R., GERLACH, J., MOLANDER, L., KJELLBERG, B. \& SCHEELKRUGER, J. (1976). Mania, depression and brain dopamine. In Current Developments in Psychopharmacology, II, ed. Essman, W.B. \& Valzelli, L. New York: Spectrum.

SCHACHT, U. \& HEPTNER, W. (1974). Effect of nomifensine (HOE 984), a new antidepressant on uptake of noradrenaline and serotonin and on release of noradrenaline in rat brain synaptosomes. Biochem. Pharmac., 23, 3413-3422.

SCHILDKRAUT, J.J. (1965). The catecholamine hypothesis of affective disorders: a review of supporting evidence. Am. J. Psychiat., 122, 509-522.

SHEPHERD. M., LADER, M. \& RODNIGHT, R. (1968). Clinical Psychopharmacology. London: English Universities Press.

STEWART, R.B. \& CLUFF, L.E. (1972). A review of medication errors and compliance in ambulant patients. Clin. Pharmac. Ther., 13, 463-468.

TAEUBER, K., RUPP, W., BRETTEL, H.F., GAMMEL, G. \& BENDER, R. (1976). Untersuchungen uber Wechselwirkungen zwischen einem Psychopharmakon (Nomifensin) und Alkohol. Blutalkohol, 13, 3-16.

TRIMBLE, M., ANLEZARK, G. \& MELDRUM, B. (in 
press). Seizure activity in photosensitive baboons following antidepressant drugs and the role of serotoninergic mechanisms. Psychopharmacologia Berl.

UNGERSTEDT, V. (1971). Adipsia and aphagia after 6hydroxydopamine-induced degeneration of the nigrostriatal dopamine system. Acta physiol. Scand., suppl. 367, 95-122.

WITTENBORN, J.R., FLAHERTY, C.F. Jr, MCGOUGH, W.E., BOSSANGE, K.A. \& NASH, R.J. (1976). A

\section{Discussion}

PROFESSOR JENNER, summing up the day's proceedings, said that there was evidence that nomifensine was active in the treatment of depression and that it was certainly an interesting compound. He would like to see the placebo study reported by $\mathrm{Dr}$ Taueber repeated, and if the same results were found, he would accept that as evidence that nomifensine was a very powerful antidepressant. The results reported from Edinburgh, Dumfries and Newcastle were what he would have expected from comparison of the effect of imipramine, nomifensine and placebo on the psychomotor performance of normal males. Psychopharmacology, 51, 85-90.

ZELLER, E.A., BARSKY, J., FOUTS, J.R., KIRCHENHEIMER, W.F. \& VAN ORDEN, L.S. (1952). Influence of isonicotinic acid hydrazide (INH) and 1-isonicotinyl-2-isopropyl hydrazide (IIH) on bacterial and mammalian enzymes. Experentia, 8, 349350.

trials of limited size. On the other hand, Professor Grof presented good evidence in favour of nomifensine, which, again, he would like to see repeated. He was sure that the drug would enjoy a future in the real world, but, referring to the discussions about dependence, he would like to remind the audience how complicated a subject psychiatry was, and in particular how complicated the area of dependence. 